\title{
Atypical manifestations of gastro-oesophageal reflux
}

\author{
W J Issing MD P D Karkos AFRCSI
}

J R Soc Med 2003;96:477-480

Gastro-oesophageal reflux disease (GORD) refers to the symptoms and complications of abnormal passage of gastric contents into the oesophagus. Symptoms of GORD commonly include heartburn and acid regurgitation. Apart from this typical presentation of GORD, extra-oesophageal reflux disease often results in oral, pharyngeal, laryngeal and pulmonary disorders. ${ }^{1}$ Laryngopharyngeal reflux is the movement of gastric contents beyond the oesophagus up to the laryngeal and pharyngeal area. As well as pepsin and acid, gastric contents can include bile acids and pancreatic enzymes, all of which can injure tissues not adapted to them. Laryngopharyngeal reflux is known to contribute to posterior laryngitis, laryngeal contact ulcerations, laryngeal and pharyngeal cancer, ${ }^{2}$ subglottic stenosis and laryngospasm, dysphonias, pharyngitis, asthma, pneumonia, nocturnal choking and dental diseases. ${ }^{3}$

\section{MECHANISM OF REFLUX IN THE UPPER AERODIGESTIVE TRACT}

The mechanism of reflux-related airway disease is not well understood. A widely held view is that it arises from direct contact of acid refluxate with the laryngeal and pharyngeal mucosa. Another theory is that the acid causes the disorder by stimulating vagally mediated reflexes leading to bronchoconstriction. ${ }^{3}$ Pepsin has long been known to cause peptic ulcer disease but only in recent years has the link with upper aerodigestive tract diseases been recognized. Because pepsin is not synthesized by any cell types in the airway, the presence of pepsin in airway tissues is clear evidence that those areas have been exposed to gastric contents.

In a study reported last year by Tasker et al., ${ }^{4}$ pepsin was found in middle-ear effusions of children-an observation that generated an entirely new theory on the pathogenesis of glue ear in children. Current research focuses on developing a diagnostic tool that will identify and localize pepsin in airways tissues.

Department of Otolaryngology, Freeman Hospital, Newcastle upon Tyne NE7 7DN, UK

Correspondence to: Mr P D Karkos

E-mail: pkarkos@aol.com

\section{EPIDEMIOLOGY OF REFLUX}

Symptoms of GORD are common, with $25-40 \%$ of the British population having heartburn or acid regurgitation in the course of a week; ${ }^{5}$ in the United States 25-75 million people are affected by reflux. GORD is managed mainly in primary care and in 1998 was associated with the largest prescribing cost in the National Health Service. ${ }^{6}$ In Germany about 800000 people are affected by GORD, $10 \%$ of whom are likely to develop Barrett's oesophagus with the risk of oesophageal adenocarcinoma (GORD carries an eightfold increase in risk of adenocarcinoma and severe reflux carries a fortyfold risk). Some $80 \%$ of patients with adenocarcinoma are incurable. ${ }^{7}$ Reflux oesophagitis is associated with age. Women are more frequently affected than men but their symptoms are less severe.

\section{EXTRA-OESOPHAGEAL MANIFESTATIONS OF REFLUX}

In most patients the symptoms of GORD are heartburn and regurgitation but the patients seen by otolaryngologists complain more commonly of hoarseness, chronic cough, frequent throat clearing or globus pharyngeus. Up to $78 \%$ of patients with chronic sore throat (sore throat persisting for more than six weeks) have GORD. ${ }^{8}$ With the aid of 24 hour dual probe $\mathrm{pH}$ monitoring (the standard test for reflux detection) in patients with laryngeal changes gastric juice can be seen to pass through the upper oesophageal sphincter and 'climb' up to the larynx. The mechanism of laryngopharyngeal reflux is different from that of GORD: the primary defect may be dysfunction of the upper oesophageal sphincter. The pharynx, larynx and tracheobronchial tree are not adapted to handle reflux, and any acid reflux in the laryngopharyngeal area is potentially harmful.

\section{Reflux laryngitis}

The term reflux laryngitis (or posterior laryngitis) signifies erythematous arytenoids, a greyish appearance of the interarytenoid region, or a combination of the two. Often this finding is accompanied by oedema. Wiener et al. found a decrease in oesophagcal $\mathrm{pH}$ in $65 \%$ of patients with chronic hoarseness and suggestive laryngeal lesions, though reflux oesophagitis was demonstrable endoscopically in only $28 \%{ }^{8}$ Long-standing GORD is believed to contribute to 
the development of laryngeal cancer; chronic irritation of the laryngeal mucosa is thought to be a carcinogenic factor. ${ }^{9}$

\section{Contact granulomas}

Contact granulomas appear in the area of vocal process in the posterior third of the larynx. Voice abuse/misuse is mainly to blame, but there is evidence that reflux contributes. ${ }^{9}$ A combination of proton pump inhibitor and speech therapy is the treatment of choice rather than surgical removal. ${ }^{10}$

\section{Reinke's oedema}

This is bilateral oedema of the subepithelial space of the vocal cords, mostly found in elderly female smokers. Again, GORD may be a cofactor. Treatment consists of microsurgical removal of the oedematous mucosa. Postoperatively, proton pump inhibitors can be used together with cessation of smoking and speech therapy. ${ }^{10}$ If the patient continues to smoke postoperatively, the quality of the voice will be poor and many surgeons decline to operate unless the patient stops smoking.

\section{Subglottic laryngeal stenosis}

Bain et al. in 1983 reported a patient with GORD, without any history of trauma, intubation or surgery, who had developed subglottic laryngeal stenosis. ${ }^{11}$ After laryngeal reconstruction of the airways and Nissen fundoplication the condition did not recur. Subglottic stenosis has been linked to reflux in children as well as adults. ${ }^{12,13}$ Koufman, with pH-metry, demonstrated reflux in 24 (75\%) of 32 patients with this condition. ${ }^{14}$ The combination of GORD and laryngeal trauma (including iatrogenic injuries such as intubation) creates the ideal environment for development of subglottic stenosis.

\section{Postnasal drip}

Only 20\% of GORD patients describe heartburn or retrosternal pain. One of the atypical symptoms is postnasal drip, also known as catarrh, though clearly this can have other reasons. There is much confusion about the origin of this reflux symptom. Many patients are convinced that the annoying mucus originates from the nose or the paranasal sinuses but in most cases there is no evident disease in these sites. In a study of 250 patients with reflux and without any paranasal sinus disease, postnasal drip was present in more than three-quarters (Issing WJ, unpublished). A possible mechanism is reflux-related damage to the ciliated epithelium of the posterior larynx and pharynx, leading to disruption of tracheal clearance; the patient gets the feeling of constant secretions and keeps clearing the throat. Only why postnasal drip is an early manifestation of GORD. However, postnasal drip is a vague and common symptom, and treatment of underlying GORD may be long delayed. ${ }^{15}$ Otolaryngologists and general practitioners usually prescribe decongestant nasal sprays. In cases where symptoms persist for months, proton pump inhibitors may prove useful.

\section{Globus pharyngeus}

The most common symptom reported by patients with laryngopharyngeal reflux is a lump in the throat (globus pharyngeus). As early as 1969 Malcomson found a link between reflux and globus pharyngeus. With the aid of barium studies he was able to demonstrate hiatus hernia with reflux in 63\% of 307 patients with globus sensation. Subsequent studies gave conflicting results. ${ }^{16}$ Koufman $^{14}$ reported a decrease in oesophageal $\mathrm{pH}$ in 16 (58\%) of 27 patients, whereas Wilson et al. found this to be the case in only $20(23 \%)$ of 87 globus patients. ${ }^{17}$ Hill et al. found no difference in psychological state between patients with globus and a control group. They reported GORD in $31 \%$ of patients. ${ }^{18}$ Overall, it is still unclear whether reflux contributes to the aetiology of globus. The coexistence of globus and reflux does not mean that reflux is the cause. ${ }^{19}$

\section{GORD and teeth}

The ill-effects of gastric juice on tooth enamel have been known for many years. Conditions such as anorexia nervosa, bulimia, vomiting of pregnancy, chronic vomiting, alcoholic gastritis, and hiatus hernia have long been linked with tooth erosion. Schroder et al. found that 55\% of patients with GORD had typical changes in teeth, compared with $10 \%$ of a control group. ${ }^{20}$

\section{GORD and the airway}

Up to $60 \%$ of patients with asthma have GORD and two theories exist for the association. According to the first, reflux generates bronchoconstriction by stimulation of vagal reflexes. The second proposes that the bronchoconstriction is due to microaspiration of gastric juices, worsened by the widely used anti-asthma drug theophylline. May et al. ${ }^{21}$ showed that theophylline increases both gastro-oesophageal reflux and reflux-related dyspnoea. This could be explained by the muscle-relaxant effect of theophylline on the lower oesophageal sphincter. In children, ${ }^{22}$ microaspiration might sometimes account for apnoea, laryngospasm, croup and even sudden infant death syndrome. Reflex bronchoconstriction 'posing' as a defence mechanism is of central importance here. 


\section{Non-cardiac chest pain}

The possibility of reflux should be considered in cases of atypical angina pectoris with normal electrocardiogram or normal coronary angiogram. In a study of 108 patients with atypical chest pain, 12 were found to have gastrointestinal causes for their pain, ${ }^{23}$ and in other studies ${ }^{24} 25-50 \%$ of patients with pain of non-cardiac origin proved to have GORD. Differential diagnosis is difficult because the incidence of both GORD and coronary artery disease rises with age and body inactivity and these conditions may coexist and influence each other. For example, GORD can cause a drop in blood pressure and a rise in heart rate, which in turn may lead to angina pectoris and electrocardiographic changes.

\section{Reflux and carcinoma of the upper aerodigestive tract}

Only a few years ago reflux was judged trivial and not a real disease. Today we recognize the hazard of carcinogenesis. ${ }^{2}$ Almost $5 \%$ of patients with laryngeal cancer are nonsmokers, and reflux is suspected of being the main factor in this group. Both tobacco smoke and alcohol increase acid reflux, so these may interact in smokers and drinkers. Among patients with various otolaryngological disorders the highest prevalence of reflux was in those with carcinoma. ${ }^{14}$ However, the exact relation between reflux and carcinoma remains unclear.

\section{TREATMENT}

About $60 \%$ of patients with heartburn self-medicate and do not seek professional help. There is a popular opinion that reflux symptoms can be controlled by lifestyle modifications alone, such as smoking cessation, weight loss, decrease of fatty food intake, alcohol and coffee and change in sleep position, but the efficacy of such measures has not been proven by controlled studies. On the other hand, lifestyle modification plus drug treatment is the standard management for patients with laryngopharyngeal reflux. 60-90\% of patients treated in this way had improvements or resolution of symptoms including globus, dysphagia, reflux laryngitis and chronic cough. ${ }^{1,14}$

Since motility disorders are crucial in GORD, prokinetic drugs might seem the best approach. One such was cisapride, which along with metoclopramide and domperidone gave convincing results. As well as the motility effect, it increased production of saliva and bicarbonate. ${ }^{25}$ However, this agent has cardiac side-effects and is no longer used. At present proton pump inhibitors are the treatment of choice for laryngopharyngeal reflux, primarily because of their prophylactic effect. They act on parietal cells when $\mathrm{pH}$ is less than 4 and irreversibly inactivate $\mathrm{H}^{+} / \mathrm{K}^{+}$ATPase. ${ }^{26}$ Lengthy 'step-up' regimens with increasing doses of drugs are no longer used for laryngopharyngeal reflux, mainly because of the delay in healing and the high costs. More effective and cost-effective is 'step-down therapy', whereby the patient starts on a high dose of proton pump inhibitor such as esomeprazole $40 \mathrm{mg}$ daily for 8 weeks and twice daily for non-responders. ${ }^{27}$ The standard GORD dose and duration is not adequate in laryngopharyngeal reflux and many patients relapse when treatment stops. ${ }^{28}$ The argument for twice-daily dosing is that none of the proton pump inhibitors suppresses acid for more than 17 hours. ${ }^{29}$ Treatment should continue for six months or longer, with regular review to monitor response and adjust dosage.

Anti-reflux surgery, such as Nissen fundoplication, ${ }^{30}$ is indicated in selected patients whose symptoms persist despite medication for at least a year. The case for surgery is strongest in those with typical reflux that is not improved by proton pump inhibitors and those with an associated hiatus hernia. Long-term follow-up shows no advantages for open fundoplication over use of proton pump inhibitors. For laparoscopic fundoplication the evidence does not yet exist.

\section{REFERENCES}

1 Tauber S, Gross M, Issing WJ. Association of laryngopharyngeal symptoms with gastroesophageal reflux disease. Laryngoscope 2002;112:879-86

2 El-Serag HB, Hepworth EJ, Lee P, Sonnenberg A. Gastroesophageal reflux disease is a risk factor for laryngeal and pharyngeal cancer. Am J Gastroenterol 2001;96:2013-8

3 Koufman JA, Armin MR, Panetti M. Prevalence of reflux in 113 consecutive patients with laryngeal and voice disorders. Otolaryngol Head Neck Surg 2000;123:385-8

4 Tasker A, Dettmar PW, Panetti M, Koufman JA, Birchall J, Pearson JP. Is gastric reflux a cause of otitis media with effusion in children? Laryngoscope 2002;112:1930-4

5 Raghunath A, Hungin PS, Woof D, Childs S. Prevalence of Helicobacter pylori in patients with gastro-oesophageal reflux disease: systematic review. BMJ 2003;326:737

6 Office of Health Economics. Health Expenditures in the UK. London: Stationery Office, 1996

7 Gerards C, Peitz U, Malfertheiner P. Reflux oesophagitis: a community wide increase in incidence. Ther Umsch 2001;58:137-45

8 Weiner GJ, Koufmann JA, Wu WC, Cooper JB, Richter JE, Castell DO. Chronic hoarseness secondary to gastroesophageal reflux disease: documentation with 24-h ambulatory $\mathrm{pH}$ monitoring. Am J Gastroenterol 1989;84:1503-8

9 Ylitalo R, Ramel S. Extraesophageal reflux in patients with contact granuloma: a prospective controlled study. Ann Otol Rhinol Laryngol 2002; 111:441-6

10 Toohill RJ, Kuhn JC. Role of refluxed acid in pathogenesis of laryngeal disorders. Am J Med 1997;103:100-6

11 Bain WM, Harington JW, Thomas LE. Head and neck manifestations of gastroesophageal reflux. Laryngoscope 1983;93:175-9

12 Halstead LA. Gastroesophageal reflux: a critical factor in pediatric subglottic stenosis. Otolaryngol Head Neck Surg 1999;120:683-9

13 Maronian NC, Azadeh H, Waugh P, Hillel A. Association of laryngopharyngeal reflux disease and subglottic stenosis. Ann Otol Rhinol Laryngol 2001;110:606-12 
14 Koufman JA. The otolaryngologic manifestations of gastroesophageal reflux disease: a clinical investigation of 225 patients using 24-hour ambulatory $\mathrm{pH}$ monitoring and an experimental investigation of the role of acid and pepsin in the development of laryngeal injury. Laryngoscope 1991;101(suppl 53):1-78

15 Hanson DG, Lang JJ. Diagnosis and management of chronic laryngitis associated with reflux. Am J Med 2000;108:112-19

16 Malcomson KG. Radiological findings in globus hystericus. Br J Radiol 1969;39:583-6

17 Wilson JA, Pryde A, Piris A. Pharyngoesophageal dysmotility in globus sensation. Arch Otolaryngol Head Neck Surg 1987;115:1086-90

18 Hill J, Stuart RC, Fung HC, et al. Gastroesophageal reflux, motility disorders and psychological profiles in the etiology of globus pharyngis. Laryngoscope 1997;107:1373-7

19 Smit CF, Mathus-Vliegen LM, Devriese PP, Schouwenburg PF, Kupperman D. Diagnosis and consequences of gastropharyngeal reflux. Clin Otolaryngol 2000;25:440-55

20 Schroeder PL, Filler SJ, Ramirez B, Lazarchic DA, Vaezi MF, Richter JE. Dental erosion and acid reflux disease. Ann Intern Med 1995; 122:809-15

21 May B, Micklefield G, Schott D. Esophageal motility disorders, gastroesophageal reflux and obstructive respiratory tract diseases. Pneumologie 1991;45:389-91

22 Gumpert L, Kalach N. Hoarsness and gastroesophageal reflux in children. J Laryngol 1998;112:49-54
23 Spalding L, Reay E, Kelly C. Cause and outcome of atypical chest pain in patients admitted to hospital. $J$ R Soc Med 2003;96: $122-5$

24 Devault KR. Overview of therapy for the extraoesophageal manifestations of gastroesophageal reflux disease. Am $J$ Gastroenterol 2000;95:39-44

25 Goldin GF, Marcinkeiwicz M, Zbroch T. Esophagoprotective potential of cisapride. An additional benefit for gastroesophageal reflux disease. Dig Dis Sci 1997;42:1362-9

26 Bough ID, Sataloff RT, Castell DO, Hills JR, Gideon RM, Spiegel JR. Gastroesophageal reflux laryngitis resistant to omeprazole therapy. $J$ Voice 1995;9:205-11

27 DelGaudio JM, Waring JP. Empiric esomeprazole in the treatment of laryngopharyngeal reflux. Laryngoscope 2003;113: 598-601

28 Hamdan AL, Sharara AI, Younes A, Fuleihan N. Effect of aggressive therapy on laryngeal symptoms and voice characteristics in patients with gastroesophageal reflux. Acta Otolaryngol 2001; 121:868-72

29 Kahrilas PJ, Falk GW, Johnson DA. Esomeprazole improves healing and symptom resolution as compared with omeprazole in reflux oesophagitis patients: a randomised controlled trial. Aliment Pharmacol Ther 2000; 14:1249-58

30 Kahrilas PJ. Gastroesophageal reflux disease. JAMA 1996;276: 983-8 